\title{
Tunceli Uzunçayır Barajı Mansap Tarafında Su Kalitesinin Araştırılması ve İzlenmesi
}

\author{
Emine Işıl Arslan Topal ${ }^{*}$ \\ Fırat Üniversitesi, Mühendislik Fakültesi, Çevre Mühendisliği Bölümü, Elazığ, Türkiye (ORCID: 0000-0003-0309-7787)
}

(İlk Geliş Tarihi 1 Mayıs 2020 ve Kabul Tarihi 26 Haziran 2020)

(DOI: 10.31590/ejosat.740012)

ATIF/REFERENCE: Arslan Topal, E. I. (2020). Tunceli Uzunçayır Barajı Mansap Tarafinda Su Kalitesinin Araştırılması ve İzlenmesi. Avrupa Bilim ve Teknoloji Dergisi, (19), 596-605.

$\ddot{O} \mathbf{z}$

Bu çalışmada, Tunceli Uzunçayır Barajından mansaplanan yerüstü sularının su kalitesi belirlendi. Su kalitesinin belirlenmesinin amacı, barajlardan mansaplanan su kütlesinin hangi amaçla kullanılıp kullanılamayacağının değerlendirilmesidir. Bu çerçevede, yüksek kaliteli sular olarak da ifade edilen "çok iyi” su durumunu gösteren sular Sınıf-1 kalitesindeki sular olarak belirtilmektedir. Bu sular içme suyu olma potansiyeli yüksek olan yerüstü suları, yüzme gibi vücut teması gerektirenler dahil rekreasyonel maksatlar için kullanılabilir suları, alabalık üretimi için kullanılabilir nitelikte suları ve hayvan üretimi ve çiftlik ihtiyacı için kullanılabilir nitelikteki suları kapsamaktadır. Az kirlenmiş su olarak da ifade edilen "iyi su” durumunu gösteren sular Sınıf-2 kalitesindeki sular olarak ifade edilmektedir. Bu sular içme suyu olma potansiyeli olan yerüstü sularını, rekreasyonel maksatlar için kullanılabilir nitelikteki suları, alabalık dışında balık üretimi için kullanılabilir nitelikteki suları ve Mer-i mevzuat ile tespit edilmiş olan sulama suyu kalite kriterlerini sağlamak şartıyla sulama suyu olarak kullanılabilecek suları kapsamaktadır. Bu çalışmada, yerüstü su örnekleri 2019 yılı Haziran, Temmuz ve Ağustos aylarında alındı ve elde edilen veriler Yerüstü Su Kalitesi Yönetmeliği’nde (YSKY) verilen su kalite değerleriyle mukayese edildi. Analiz sonuçlarına göre pH değerleri 7,92-8,01 arasında değerler aldı ve su kalite sınıfı Sınıf-1 olarak belirlendi. Sıcaklık değerleri 17,2-23,1 ${ }^{\circ} \mathrm{C}$ arasında değişkenlik gösterdi. Elektriksel iletkenlik (EI) değerleri 322-384 $\mu \mathrm{S} / \mathrm{cm}$ arasında değerler aldı ve su kalite sınıfı Sınıf-1 olarak belirlendi. Nitrat azotu $\left(\mathrm{NO}_{3}{ }^{-} \mathrm{N}\right)$ konsantrasyonları 0,91-1,26 mg/L arasında tespit edildi ve buna göre su kalite sınıfı Sınıf-1 olarak belirlendi. Biyokimyasal oksijen ihtiyacı (BOİ 5 ) konsantrasyonları 2,1-3,5 mg/L arasında iken kimyasal oksijen ihtiyacı (KOİ) konsantrasyonları ise 17,3-25,1 mg/L arasında değerler aldığı belirlendi. Sonuç olarak, Uzunçayır Barajından mansaplanan yerüstü sularının pH, sıcaklık, Eİ, $\mathrm{NO}_{3}{ }^{-}-\mathrm{N}, \mathrm{BOI}_{5}$ konsantrasyonları açısından Sınıf-1 kalitesinde, KOİ açısından ise Sınıf-2 kalitesinde olduğu tespit edildi.

Anahtar Kelimeler: Baraj, Su kalitesi, Tunceli, Uzunçayır, Yerüstü suları.

\section{Investigation and Monitoring of The Water Quality at Downstream Side of Tunceli Uzuncayir Dam}

\begin{abstract}
In this study, water quality of surface waters of downstream from Tunceli Uzuncayir Dam was determined. The purpose of determining the water quality is to evaluate for what purpose the water mass downstream from the dams can or can not be used. In this context, waters that show "very good" water status, also referred to as high quality waters, are specified as Class-1 waters. These waters include surface waters with high potential for drinking water, water that can be used for recreational purposes, including those that require body contact, such as swimming, water that can be used for trout production, and water that can be used for animal production and farm needs. The waters showing the status of "good water", which is also referred to as less polluted water, are referred to as Class-2 quality waters. These waters include surface waters with the potential to be drinking water, waters that can be used for recreational purposes, waters that can be used for fish production other than trout, and waters that can be used as irrigation
\end{abstract}

* Sorumlu Yazar: Fırat Üniversitesi, Mühendislik Fakültesi, Çevre Mühendisliği Bölümü, Elazığ, Türkiye, ORCID: 0000-0003-0309-7787, eiarslan@ firat.edu.tr 
water provided that they meet the irrigation water quality criteria determined by the regulation. In this study, surface water samples were taken in June, July, and August (Summer) in 2019 and the data obtained were compared with the water quality values given in the Surface Water Quality Regulation (SWQR). According to the results of the analysis, pH values were between 7.92-8.01 and the water quality class was determined as Class-1. Temperature values were show changes between $17.2-23.1^{\circ} \mathrm{C}$. The electrical conductivity (EC) values took values between $322-384 \mu \mathrm{S} / \mathrm{cm}$ and the water quality class was determined as Class-1. Nitrate nitrogen $\left(\mathrm{NO}_{3}{ }^{-} \mathrm{N}\right)$ concentrations determined between $0.91-1.26 \mathrm{mg} / \mathrm{L}$ and according to these results, water quality class was determined as Class-1. Biochemical oxygen demand $\left(\mathrm{BOD}_{5}\right)$ concentrations were between 2.1-3.5 mg/L while chemical oxygen demand (COD) concentrations ranged between 17.3-25.1 mg/L. As a result, it was determined that surface waters of downstream from Uzunçayır Dam are Class-1 quality in terms of $\mathrm{pH}$, temperature, $\mathrm{EC}, \mathrm{NO}_{3}^{-}-\mathrm{N}, \mathrm{BOD}_{5}$ concentrations and Class-2 quality in terms of COD.

Keywords: Dam, Water quality, Tunceli, Uzuncayir, Surface waters.

\section{Giriş}

Dünya nüfusunun artışına paralel olarak her geçen gün su ihtiyacı da artmaktadır. Hızlı kentleşme ve endüstrileşmeye bağlı olarak artan su tüketimi atıksu miktarının artmasına ve temiz su kaynaklarının kirlenmesine neden olmaktadır. Bu nedenle, su kaynaklarının iyi yönetilmesi ve sürdürülebilir su kullanımının sağlanması gerekmektedir. Sürdürülebilir su kullanımı yönetim stratejilerini uygulamak için su kalitesi ve kirlilik kaynakları hakkında bilgi sahibi olmak önemlidir (Crosa ve ark., 2006; Sarkar ve ark., 2007; Zhou ve ark., 2007; Huang ve ark., 2014; Korkanç ve ark., 2017; Cikcikoglu ve ark., 2018). Nüfus artış1, düzensiz kentleşme ve sanayileşme, tarımda kimyasalların aşırı kullanımı (gübreler ve böcek ilaçları gibi), evsel atıksuların boşaltılması ve vadilere vahşi katı atık depolanması sular üzerinde ciddi baskı oluşturmaktadır (Ustaoğlu ve Tepe, 2019). Bu durum nehir sistemlerinin doğal yapısını bozmakta ve su kalitesinin günden güne bozulmasına neden olmakta ve dünyadaki temel çevre sorunlarından biri haline gelmektedir (Ustaoğlu ve ark., 2020).

Göller ve rezervuarlar, vazgeçilmez ekolojik değerlere sahip olan ve insan tüketimine kolayca erişilebilen en büyük yüzey tatlisu envanterini sağlayan hidrosferin hayati derecede önemli bileşenleridir (Herdendorf, 1982, Herdendorf, 1990, Lehner ve Döll, 2004; Wang ve ark., 2014). Bu nedenle hem doğal göllerin hem de yapay göllerin su kalitesini belirlemek oldukça önemlidir. Çünkü, su kalitesinin belirlenmesi suyun kullanım amacını belirler. Tüm su kullanımları arasında, tarım baskın kullanıcıdır ve sulu tarım dünyadaki su kaynaklarının yaklaşık \%70'ini tüketmektedir (Galán-Martín ve ark., 2017; Li ve ark, 2020a). Bununla birlikte, tarımsal su kıtlığı, endüstriyel, evsel, ekolojik ve çevresel kullanımlar gibi tarım dışı sektörlere yönelik su talebinin hızla artması nedeniyle artan baskıya maruz kalmaktadır (Levidow ve ark., 2014, Jiang ve ark., 2016; Li ve ark., 2020a). Su kalitesinin bozulmas1, küresel düzeyde halk sağlığı için birincil tehdittir (Rahman ve ark., 2020). Atıksuların iyi arıtılamaması, sanayi atıksuları ve kimyasalların tarımda sistematik olmayan kullanımı gibi antropojenik etkiler, su kalitesinin kötüleşmesinde hayati öneme sahiptir (Azizullah ve ark., 2011; Shirani ve ark., 2018; Subedi ve ark., 2019; Iqbal ve ark., 2020; Li ve ark., 2020b; Bashir ve ark., 2020). Bu nedenle, içme suyu (halk sağlığı) ve ham su (sucul yaşam ve sulama) kalitesi hakkında artan farkındalık ile yüzey suyu özelliklerinin değerlendirilmesi önemlidir (Ouyang, 2005; Paca ve ark., 2019).

Büyük nehir havzaları, özellikle tek tek ülkelerin yasama çerçevelerinde ve su kaynakları yönetimi önceliklerinde farklılık gösterebildikleri çok uluslu havzalarda, su kalitesi izleme ve yönetimi konusunda birçok zorluk oluşturmaktadır (Sommerwerk ve ark., 2010; Bloesch ve ark., 2012). Bu nedenle, su kalitesinin izlenmesi, insan faaliyetlerinin etkilerini, suyun insan kullanımına uygunluğunu ve tortu ve kirleticilerin göllere ve kıyı bölgelerine akılarını (konsantrasyonlar ve deşarj ölçümleri yoluyla) belirlemede önemlidir (Chapman ve ark., 2016; Bayhan ve ark., 2017).

Bu çalışmada Yukarı Fırat Karasu Çayı Alt Havzasında yer alan Tunceli ilinin önemli su yapılarından biri olan ve Munzur Nehri üzerine kurulu olan Uzunçayır Barajından mansaplanan yerüstü sularının kalitesi bazı parametrelerle belirlendi. Bu çalışmanın literatürdeki diğer çalışmalardan farkı hem Uzunçayır Barajından mansaplanan yerüstü sularının kalitesinin belirlendiği bir çalışma olmaması hem de parametreler arasındaki ilişkiyi inceleyen bir istatistiksel çalışma yapılmamasıdır.

\section{Materyal ve Metot}

\subsection{Materyal}

Çalışma alanı olarak Tunceli ilinin önemli su kaynaklarından olan Munzur nehrinin üzerine kurulu Uzunçayır Barajının mansap alanı seçildi. Uzunçayır Barajı, Yukarı Fırat Karasu Çayı Alt Havzasında bulunan bir barajdır ve hidroelektrik enerji üretimi gerçekleştirilir. Uzunçayır Baraj Gölü farklı şekillerde kirleticilere maruz kalmaktadır. Bu nedenle, Uzunçayır Barajından mansaplanan suların su kalitesinin belirlenmesi ve sürekli izlenmesi gerekmektedir. Çalışma alanı Şekil 1'de gösterilmiştir. Çalışmada Uzunçayır Barajından mansaplanan suların su kalitesini belirlemek amacıyla yerüstü su numuneleri Mazgirt köprüsü mevkiinden alındı. Uzunçayır Barajının mansap tarafının çalışma alanı olarak seçilme nedeni mansaplanan suların sulama suyu olarak tarım arazilerinde kullanılmasıdır. Bu amaçla, Tunceli Uzunçayır Barajı mansap tarafından yerüstü su numuneleri 2019 yılı Haziran, Temmuz ve Ağustos (yaz mevsimi) aylarında 10., 20. ve 30. günde kompozit numune olacak şekilde 5 farklı örnekleme noktasından alındı. Örnekleme noktalarına (ÖN) ait ED50 6 derecelik koordinatlar Tablo 1'de verilmiştir. Alınan yerüstü su numuneleri numune kaplarına aktarıldı. Numunelerde $\mathrm{pH}$, sıcaklık, elektriksel iletkenlik, Kimyasal Oksijen İhtiyacı (KOI), nitrat azotu (NO$\left.{ }_{3}^{-}-\mathrm{N}\right)$, Biyokimyasal Oksijen İhtiyacı (BOİ $)$ parametreleri analiz edildi. Bu çalışmada, yaz mevsiminin seçilme nedeni tarımsal faaliyetlerin yoğun olması nedeniyle Uzunçayır Barajından mansaplanan suların sulama suyu ve kullanma suyu olarak tercih edilmesidir. 
Tablo 1. Örnekleme noktalarına ait koordinatlar

\begin{tabular}{|c|c|c|}
\hline \multirow{2}{*}{ Noktalar } & \multicolumn{2}{|c|}{ Koordinatlar* } \\
\cline { 2 - 3 } & $\mathbf{X}$ & Y \\
\hline ÖN-1 & 547182 & 4312164 \\
\hline ÖN-2 & 547159 & 4312185 \\
\hline ÖN-3 & 547157 & 4312160 \\
\hline ÖN-4 & 547132 & 4312150 \\
\hline ON-5 & 547116 & 4312168 \\
\hline
\end{tabular}

*Koordinatlar Magellan eXplorist 510 (Santa Clara, USA) cihazı kullanılarak elde edilmiştir.

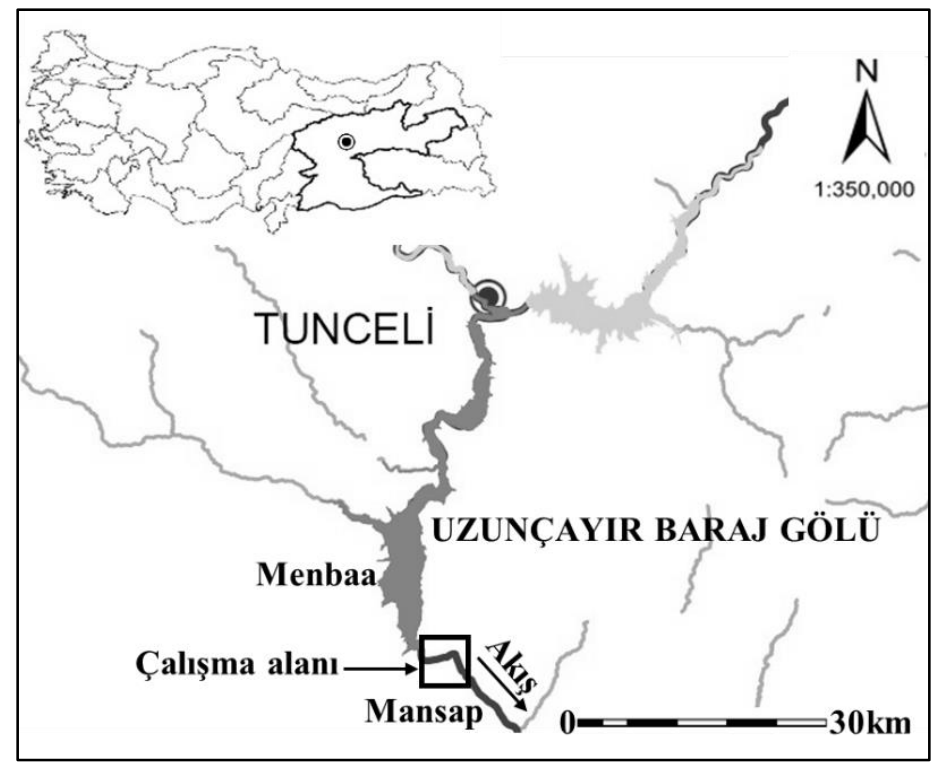

Şekil 1. Çalışma alanı

\subsection{Metot}

Uzunçayır Barajından mansaplanan yerüstü sularında fizikokimyasal parametrelerden pH, sıcaklık ve Eİ değerleri ile kimyasal oksijen ihtiyacı (KOİ), biyokimyasal oksijen ihtiyacı $\left(\mathrm{BOI}_{5}\right)$, nitrat azotu $\left(\mathrm{NO}_{3}^{-}-\mathrm{N}\right)$ konsantrasyonları belirlendi. Yerüstü su numunelerinin pH, sıcaklık ve Eİ değerleri Hach Lange 40d pH, elektriksel iletkenlik ve çözünmüş oksijen ölçer cihazı kullanılarak, BOİ 5 ve KOİ konsantrasyonları (BOİ tespiti için hazır kit: LCK554, Hach Lange ve KOİ tespiti için hazır kit: LCI500, Hach Lange) Hach Lange DR3800 model spektrofotometre ile spektrofotometrik yöntem kullanılarak belirlendi. $\mathrm{NO}_{3}^{-}-\mathrm{N}^{-}$konsantrasyonları ise Nova60 model spektrofotometre ile spektrofotometrik yöntem (hazır kit: Nova60-14987, Merck) kullanılarak belirlendi.

\section{3. İstatistiksel Analizler}

Bu çalışmada elde edilen verilerin istatistiksel analizi, IBM SPSS Statistics 21 programı (ABD) kullanılarak gerçekleştirildi. Çalışmada alınan yerüstü su örneklerinin her biri için analizler 3 paralel olacak şekilde gerçekleştirildi. Çalışmada elde edilen verilerin ortalaması alındı ve standart hata değerleri hesaplandı. Standart hata değerleri grafiklerde ayrıca gösterildi. IBM SPSS İstatistik 21 program yazılımı kullanılarak, Haziran, Temmuz ve Ağustos ayları için her bir parametre arasındaki ilişki iki yollu Pearson korelasyon testi kullanılarak belirlendi.

\section{Araştırma Sonuçları ve Tartışma}

Çalışma kapsamında Tunceli ili Uzunçayır Barajından mansaplanan yerüstü sularının su kalitesinin belirlenmesi amacıyla pH, sıcaklık ve Eİ parametreleri ile $\mathrm{BOİ}_{5}$, KOİ ve $\mathrm{NO}_{3}^{-}-\mathrm{N}$ parametreleri yaz sezonu boyunca analiz edildi. Analiz sonuçları 30.11 .2012 tarih ve 28483 sayılı Resmi Gazete'de yayınlanarak yürürlüğe giren Yerüstü Su Kalitesi Yönetmeliği (YSKY) ile mukayese edildi. Ayrıca, aylara göre her bir parametre arasındaki ilişki istatistiksel olarak değerlendirildi. Yönetmeliğin ana amacı; yerüstü sular ile kıyı ve geçiş sularının biyolojik, kimyasal, fiziko-kimyasal ve hidromorfolojik kalitelerinin belirlenmesi, sınıflandırılması, su kalitesinin ve miktarının izlenmesi, bu suların kullanım maksatlarının sürdürülebilir kalkınma hedefleriyle uyumlu bir şekilde koruma kullanma dengesi de gözetilerek ortaya konulması, korunması ve iyi su durumuna ulaşılması için alınacak tedbirlere yönelik usul ve esasların belirlenmesidir (YSKY, 2012). YSKY'nde yerüstü su kütlelerinde bazı parametreler için çevresel kalite standartları ve kullanım maksatları ayrıntılı bir şekilde açıklanmış ve Ek-5 Tablo 2'de su kalite kriterleri verilmiştir. Yönetmelik incelendiğinde su kalite sınıfları dört kısma ayırt edilmiş ve çok iyi, iyi, orta ve zayıf olarak su kalite sınıfları belirlenmiştir. Bu kapsamda elde edilen veriler değerlendirilmiş ve aşağıda ayrıntılı bir şekilde tartışılmıştır. 


\section{1. pH, Sicaklık ve EI}

Uzunçayır Barajından mansaplanan yerüstü sularından Haziran, Temmuz ve Ağustos aylarında alınan su örneklerinde tespit edilen $\mathrm{pH}$, sicaklık ve Eİ değerleri Şekil 2'de verilmiştir.

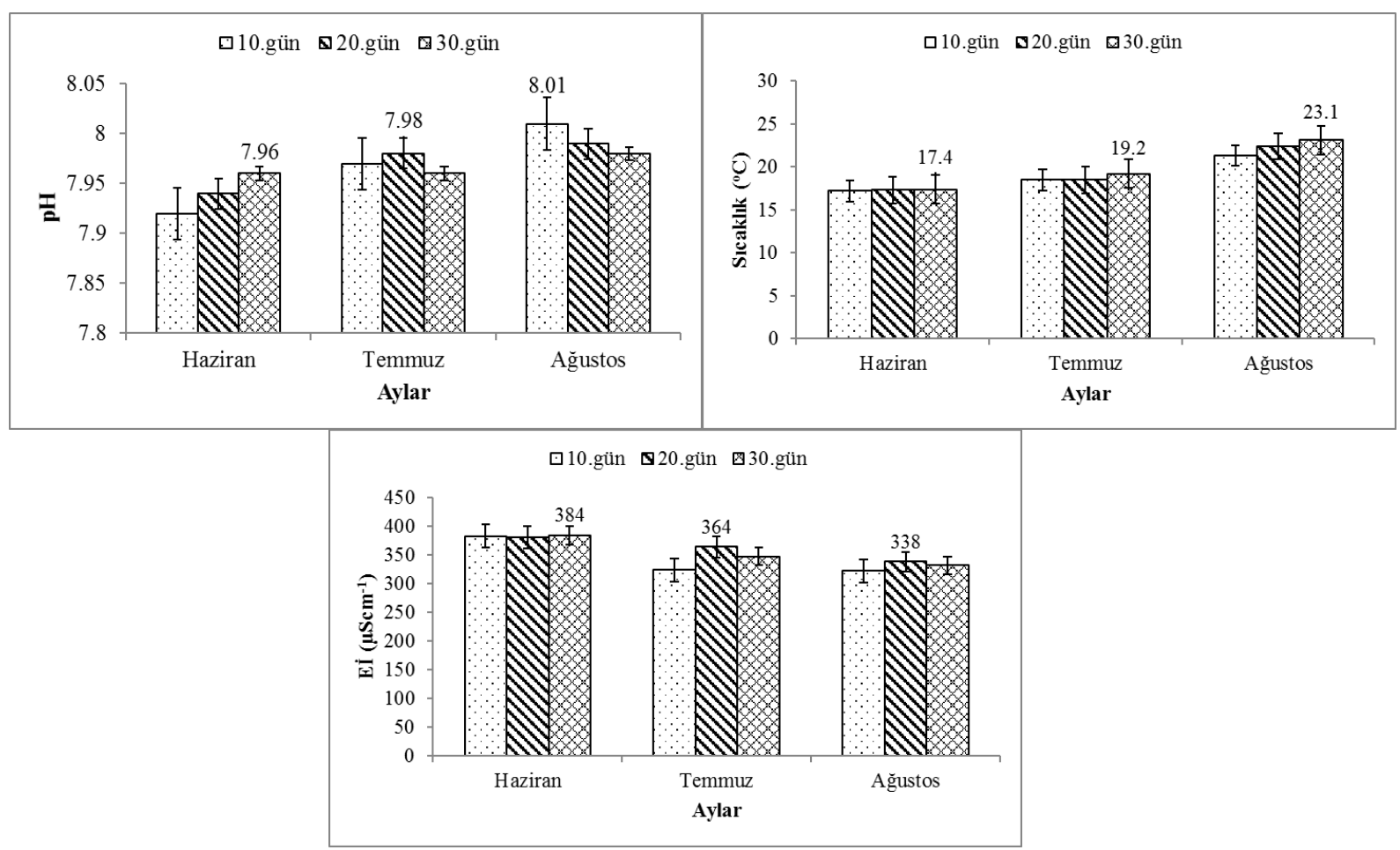

Şekil 2. Uzunçayır Barajından Mansaplanan yerüstü sularının pH, sıcaklık ve EI değerleri

Şekil 2'de gösterilen $\mathrm{pH}$ değerleri her bir aya göre değerlendirildiğinde en yüksek pH değerinin Ağustos ayında 10. gün 8,01 olarak, en düşük pH değerinin ise Haziran ayında 10. gün 7,92 olarak tespit edildi. Haziran ayında yerüstü sularında en yüksek pH değeri 30. gün 7,96 olarak belirlenirken 20. gün ise 7,94 olarak belirlendi. Haziran ayının ortalama pH değerinin 7,94 olduğu tespit edildi. Haziran ayında $\mathrm{pH}$ değerlerinin çok fazla değişiklik göstermediği belirlendi. Yerüstü sularının Temmuz ayı pH değerleri incelendiğinde en yüksek pH değeri 20. gün 7,98 olarak, en düşük pH değeri 30. gün 7,96 olarak belirlenirken 10. gün pH değeri 7,97 olarak tespit edildi. Temmuz ayında ortalama $\mathrm{pH}$ değeri 7,97 olarak belirlendi ve Haziran ayında olduğu gibi farklı günlere göre tespit edilen $\mathrm{pH}$ değerleri çok değişiklik göstermedi. Ağustos ayı $\mathrm{pH}$ değerleri değerlendirildiğinde Uzunçayır Barajından mansaplanan yerüstü sularının $\mathrm{pH}$ değerlerinin 7,98-8,01 arasında olduğu ve en yüksek $\mathrm{pH}$ değerinin $(\mathrm{pH}=8,01)$ Ağustos ayının 10. gününde, en düşük $\mathrm{pH}$ değerinin $(\mathrm{pH}=7,98)$ ise Ağustos ayının 30. gününde olduğu belirlendi. Ağustos ayının 20. gününde alınan yerüstü su örneklerinde $\mathrm{pH}$ değeri 7,99 olarak tespit edildi. Ağustos ayının ortalama pH değeri 7.99 olarak hesaplandı. Yüzey sularının normal pH aralığı 6,5 ve 8,5 aralığındadır (Zhao ve ark., 2020). YSKY'nde pH için kalite kriterleri incelendiğinde her bir sınıf için pH değerlerinin 6-9 arasında olması gerektiği belirtilmiştir. Bu çalışmada $\mathrm{pH}$ değerleri 7,92-8,01 arasında değiştiğinden Uzunçayır Barajından mansaplanan yerüstü sularının su kalite sınıfı Sınıf 1 olarak (çok iyi) belirlendi. Ho ve ark. (2019) Klang Nehri' nde (Malezya) yaptıkları çalışmada nehir suyunun $\mathrm{pH}$, değerinin nehirlerin su kalitesi standardında (Malezya su kalite indeksi sınıflaması) belirtilen Sınıf 2 ve Sınıf 3 için kabul edilebilir aralık dahilinde 5,5 ve 8 arasında değiştiğini bildirmişlerdir. Köse ve ark. (2016) Porsuk Çayı' nda yaptıkları çalışmada pH aralıklarını 7,19-8,69 aralı̆ı̆ında tespit etmişlerdir. Güneş ve ark. (2008) Ergene Nehri havzasında yaptıkları çalışmada $\mathrm{pH}$ aralıklarını 7,2-9,5 olarak bildirmişlerdir.

Çalışmada izlenen parametrelerden biri sıcaklık parametresiydi. Sıcaklık değerleri incelendiğinde en yüksek sıcaklık değeri Haziran ayı için 30. gün $17,4^{\circ} \mathrm{C}$ olarak, en düşük sıcaklık 10. gün $17,2{ }^{\circ} \mathrm{C}$ olarak belirlendi. Haziran ayında 20. gün için sıcaklık değeri $17,3{ }^{\circ} \mathrm{C}$ 'di. Haziran ayının ortalama sıcaklık değeri $17,3{ }^{\circ} \mathrm{C}$ olarak hesaplandı. Haziran ayında sıcaklık değeri değişiklik göstermedi. Temmuz ayında tespit edilen en yüksek sıcaklık değeri 30 . gün $19,2^{\circ} \mathrm{C}$, en düşük sıcaklık değeri 10 . ve 20 . gün $18,5^{\circ} \mathrm{C}$ idi. Temmuz ayında Uzunçayır Barajından mansaplanan yerüstü sularının ortalama sıcaklık değeri $18,7^{\circ} \mathrm{C}$ olarak belirlendi. Temmuz ayında sıcaklık değerleri Haziran ayında olduğu gibi çok değişiklik göstermedi. Ancak, Temmuz ayı sıcaklık değerleri Haziran ayında tespit edilen sıcaklık değerlerinden yüksekti. Ağustos ayı sıcaklık değerleri incelendiğinde en yüksek sıcaklık değeri 30 . gün $23,1^{\circ} \mathrm{C}$ olarak en düşük sıcaklık değeri 10. gün $21,3{ }^{\circ} \mathrm{C}$ olarak belirlendi. Ağustos ayında mansaplanan yerüstü sularının ortalama sıcaklık değeri $22,3{ }^{\circ} \mathrm{C}$ olarak tespit edildi. Ağustos ayı sıcaklık değerleri Haziran ve Temmuz ayında tespit edilen sıcaklık değerlerine göre daha yüksekti. Aylara göre sıcaklık değerleri büyükten küçüğe doğru Ağustos $>$ Temmuz $>$ Haziran şeklinde sıralandı. Su sıcaklığının artmasının nedeni yaz mevsiminde hava sıcaklığının artmasıdır.

Çalışma kapsamında incelenen diğer bir parametre elektriksel iletkenlikti. Şekil 2'de verilen Eİ değerleri incelendiğinde Haziran ayında en yüksek Eİ değeri 30. gün $384 \mu \mathrm{S} / \mathrm{cm}$ olarak, en düşük Eİ değeri ise 20 . gün $381 \mu \mathrm{S} / \mathrm{cm}$ olarak gerçekleşti. Haziran ayında 10. gün Eİ değeri $383 \mu \mathrm{S} / \mathrm{cm}$ olarak belirlendi. Haziran ayında tespit edilen ortalama Eİ değeri $383 \mu \mathrm{S} / \mathrm{cm}$ olarak hesaplandı. Haziran 
ayında Eİ değerleri günlere göre fazla değişiklik göstermedi. Temmuz ayında tespit edilen en yüksek Eİ değeri 20. gün $364 \mu \mathrm{S} / \mathrm{cm}$, en düşük Eİ değeri 10. gün $324 \mu \mathrm{S} / \mathrm{cm}$ olarak belirlendi. Temmuz ayı ortalama EI değeri $345 \mu \mathrm{S} / \mathrm{cm}$ olarak hesaplandı. Temmuz ayında Eİ değerleri Haziran ayından Temmuz ayına kadar geçen sürede arttı, Temmuz ayından Ağustos ayına kadar geçen sürede ise azaldı. Ağustos ayında tespit edilen en yüksek Eİ değeri 20. gün $338 \mu \mathrm{S} / \mathrm{cm}$ olarak, en düşük Eİ değeri ise 10 . gün $322 \mu \mathrm{S} / \mathrm{cm}$ olarak belirlendi. Ağustos ayında 30. gün Eİ değeri $332 \mu \mathrm{S} / \mathrm{cm}$ olarak belirledi. Ağustos ayında Uzunçayır Barajından mansaplanan yerüstü sularının ortalama Eİ değeri $331 \mu \mathrm{S} / \mathrm{cm}$ olarak hesaplandı. Köse ve ark. (2016) Porsuk Çayı' nda yaptıkları çalışmada Eİ değerlerini 346-1261 $\mu \mathrm{S} / \mathrm{cm}$ aralığında tespit etmişlerdir.

YSKY'nde Eİ için kalite kriterleri incelendiğinde her bir sınıf için Eİ değerinin verildiği görülmektedir. Buna göre; Sınıf-1 kalitesindeki sular $<400 \mu \mathrm{S} / \mathrm{cm}$, Sinıf-2 kalitesindeki sular 400-1000 $\mu \mathrm{S} / \mathrm{cm}$, Sinıf-3 kalitesindeki sular 1000-3000 $\mu \mathrm{S} / \mathrm{cm}$, Sinıf-4 kalitesindeki sular $>3000 \mu \mathrm{S} / \mathrm{cm}$ olarak sınıflandırılır. Çalışmamızda da Yaz mevsimi boyunca Eİ değerleri 322-384 $\mu \mathrm{S} / \mathrm{cm}$ arasında değerler aldığından su kalite sınıfı Sınıf-1 olarak belirlendi. Turan ve Ülkü (2003) tarafından Denizli ili Gökpınar ve Çürüksu Çaylarında yapılan çalışmada bildirilen ortalama Eİ değerleri $(633-3312 \mu \mathrm{S} / \mathrm{cm})$ bu çalışmada tespit edilenlerden $(322-384 \mu \mathrm{S} / \mathrm{cm})$ oldukça yüksektir.

\subsection{Biyokimyasal Oksijen İhtiyacı}

Uzunçayır Barajından mansaplanan yerüstü sularında tespit edilen BOİ ${ }_{5}$ konsantrasyonları Şekil 3 ’te verilmiştir.

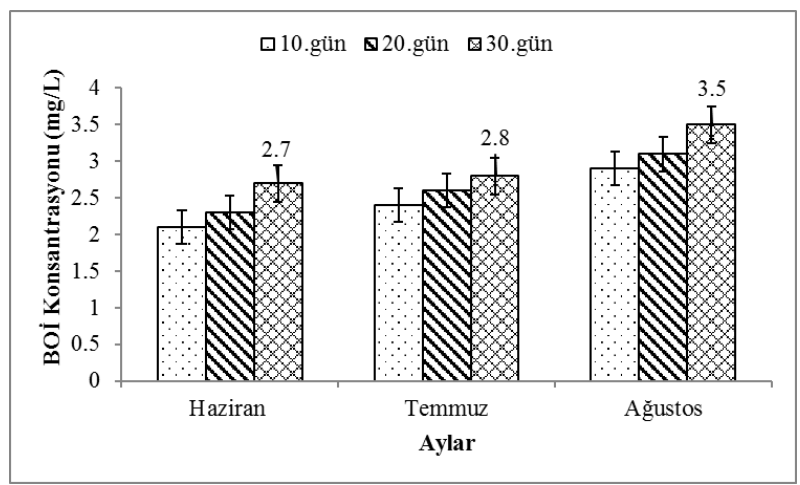

Şekil 3. Uzunçayır Barajından mansaplanan yerüstü su örneklerine ait BOİ $\dot{I}_{5}$ konsantrasyonları

Şekil 3'e göre Haziran ayında 10. günden 30. güne kadar geçen süre içerisinde BOİ ${ }_{5}$ konsantrasyonları artış gösterdi. Haziran ayında tespit edilen en yüksek $\mathrm{BOİ}_{5}$ konsantrasyonu 30 . gün $2,7 \mathrm{mg} / \mathrm{L}$ olarak, en düşük $\mathrm{BOI}_{5}$ konsantrasyonu ise 10 . gün $2,1 \mathrm{mg} / \mathrm{L}$ olarak tespit edildi. 20. günde tespit edilen BOIं ${ }_{5}$ konsantrasyonu $2,3 \mathrm{mg} / \mathrm{L}$ olarak belirlendi. Haziran ayında Uzunçayır Barajından mansaplanan yerüstü sularının ortalama $\mathrm{BOI}_{5}$ konsantrasyonu $2,37 \mathrm{mg} / \mathrm{L}$ olarak hesaplandı. Temmuz ayı $\mathrm{BOI}_{5}$ konsantrasyonları incelendiğinde Haziran ayında olduğu gibi günlere göre artış gösterdi. En yüksek BOİ 5 konsantrasyonu 30. gün 2,8 mg/L olarak tespit edilirken en düşük $\mathrm{BOI}_{5}$ konsantrasyonu 10 . gün $2,4 \mathrm{mg} / \mathrm{L}$ olarak tespit edildi. 20 . gün $\mathrm{BOI}_{5}$ konsantrasyonu $2,6 \mathrm{mg} / \mathrm{L}$ olarak belirlendi. Temmuz ayı ortalama BO $\dot{I}_{5}$ konsantrasyonu $2,6 \mathrm{mg} / \mathrm{L}$ olarak hesaplandı. Ağustos ayında tespit edilen en yüksek $\mathrm{BO}_{5}$ konsantrasyonu 30. gün $3,5 \mathrm{mg} / \mathrm{L}$ en düşük $\mathrm{BOİ}_{5}$ konsantrasyonu ise 10 . gün $2,9 \mathrm{mg} / \mathrm{L}$ olarak belirlendi. Ağustos ayında belirlenen $\mathrm{BOI}_{5}$ konsantrasyonları Haziran ve Temmuz ayına benzer bir şekilde günlere göre artı̧ gösterdi. Yaz mevsiminde Haziran ayından Ağustos ayına geçen sürede $\mathrm{BOI}_{5}$ konsantrasyonları arttı ve $\mathrm{BOI}_{5}$ konsantrasyonları açısından büyükten küçüğe doğru Ağustos $>$ Temmuz $>$ Haziran şeklinde sıralandı. Ağustos ayında ortalama $B \dot{I}_{5}$ konsantrasyonu $3,17 \mathrm{mg} / \mathrm{L}$ olarak hesaplandı. Bunun nedeni insan faaliyetleri sonucu göle giren kirleticilerin zamanla artmasından dolayıdır. Literatürde farklı nehirler için çeşitli BOİ konsantrasyonları bildirilmiştir. Zhao ve ark. (2020)' nın Yellow Nehri (Çin) kollarında yaptıkları çalışmada BOİ değerleri yaklaşık $1.5-8 \mathrm{mg} / \mathrm{L}$ arasında değişmiştir. Sözkonusu çalışmada BOİ için ulusal standart değer $4 \mathrm{mg} / \mathrm{L}$ olarak bildirilmiştir. Arman ve ark. (2019) Malezya' da Sg Berasau ve Sg Mengkibol Nehrinde yaptıkları çalışmada BOİ konsantrasyonlarını sırasıyla 4,07 ve 11,95 mg/L olarak tespit etmişlerdir. Bu sonuçlara göre Sg Berasau Sınıf 3, Sg Mengkibol ise Sınıf 4 olarak bildirilmiştir. Güneş ve ark. (2008) Ergene Nehri havzasında yaptıkları çalışmada tekstil endüstrileri organize sanayi bölgesi, deri endüstrileri organize sanayi bölgesi ve Çerkezköy ile Çorlu' daki diğer endüstrilerin atıksularını alan nehir suyunda BOİ konsantrasyonunu $534 \mathrm{mg} / \mathrm{L}$ olarak bildirmişlerdir. Turan ve Ülkü (2003) Denizli ili Gökpınar ve Çürüksu Çaylarında yaptıkları çalışmada ortalama BOİ değerlerini 18-100 mg/L olarak bildirmişlerdir. Köse ve ark. (2016) Porsuk Çayı' nda yaptıkları çalışmada BOİ konsantrasyonlarını 0,15-14,91 mg/L aralığında tespit etmişlerdir.

YSKY'nde BOİ 5 konsantrasyonu $<4 \mathrm{mg} / \mathrm{L}$ olan sular Sinıf-1 olarak; $4-8 \mathrm{mg} / \mathrm{L}$ arasında olan sular Sınıf-2 olarak; 8-20 mg/L arasında olan sular Sınıf-3 olarak ve $>20 \mathrm{mg} / \mathrm{L}$ olan sular Sınıf-4 olarak ifade edilmiștir. Çalıșmamızda da Haziran, Temmuz ve Ağustos aylarında $\mathrm{BOI}_{5}$ konsantrasyonları $4 \mathrm{mg} / \mathrm{L}$ 'den düşük değerlere sahip olduğundan $\mathrm{BO}_{5}$ açısından Uzunçayır Barajından mansaplanan yerüstü sularının su kalite sınıfı Sınıf-1 olarak belirlendi. Ho ve ark. (2019) Klang Nehri' nde (Malezya) yaptıkları çalışmada nehir suyunun Malezya su kalite indeksi sınıflamasına göre Sınıf 4 (6-12 mg/L) olduğunu gösteren $7 \mathrm{mg} / \mathrm{L}$ BOI konsantrasyonu bildirmişlerdir.

\subsection{Kimyasal Oksijen İhtiyacı}

Uzunçayır Barajından mansaplanan yerüstü sularında tespit edilen KOİ konsantrasyonları Şekil 4'te verilmiştir. 


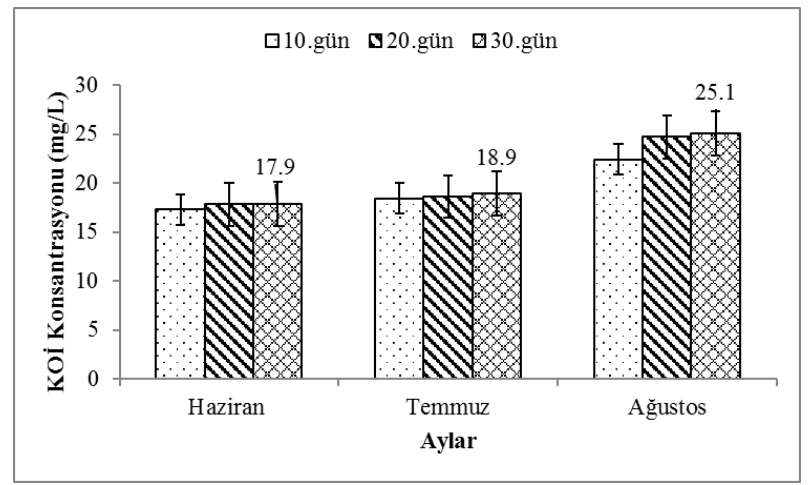

Şekil 4. Uzunçayır Barajından mansaplanan yerüstü sularına ait KOİ konsantrasyonları

Şekil 4 değerlendirildiğinde Haziran ayında 10.günden 30. güne kadar geçen sürede KOİ konsantrasyonları artış gösterdi. Haziran ayında tespit edilen en yüksek KOİ konsantrasyonu 30. gün $17.9 \mathrm{mg} / \mathrm{L}$, en düşük KOİ konsantrasyonu ise 10 . gün $17,3 \mathrm{mg} / \mathrm{L}$ olarak tespit edildi. Uzunçayır Barajından mansaplanan yerüstü sularının Haziran ayında ortalama KOİ konsantrasyonu 17,7 mg/L olarak belirlendi. Temmuz ayında KOİ konsantrasyonları Haziran ayında olduğu gibi günlere göre artış gösterdi ve en yüksek KOİ konsantrasyonu 30. gün 17,9 mg/L, en düşük KOİ konsantrasyonu ise 10. gün 18,4 mg/L olarak tespit edildi. Uzunçayı Barajından mansaplanan yerüstü sularının Temmuz ayında ortalama KOİ konsantrasyonu $18,6 \mathrm{mg} / \mathrm{L}$ olarak hesaplandı. Temmuz ayında tespit edilen KOİ konsantrasyonları Haziran ayında tespit edilen KOİ konsantrasyonlarından daha yüksekti. Ağustos ayı KOİ konsantrasyonları incelendiğinde en yüksek KOİ konsantrasyonu 30. gün 25,1 mg/L olarak en düşük KOİ konsantrasyonu 10. gün $22,4 \mathrm{mg} / \mathrm{L}$ olarak belirlendi. 20. gün tespit edilen KOİ konsantrasyonu ise $24,7 \mathrm{mg} / \mathrm{L}$ olarak tespit edildi. Uzunçayır Barajından mansaplanan yerüstü sularının Ağustos ayı ortalama KOİ konsantrasyonu 24,07 mg/L olarak hesaplandı. Ağustos ayında tespit edilen KOİ konsantrasyonları Temmuz ayında tespit edilen KOİ konsantrasyonlarından daha yüksekti. Aylara göre KOİ konsantrasyonları büyükten küçüğe doğru Ağustos>Temmuz>Haziran şeklinde siralandı.

Yaz mevsiminde KOİ konsantrasyonları $\mathrm{BOİ}_{5}$ konsantrasyonlarında olduğu gibi Haziran ayından Ağustos ayına kadar geçen sürede artmıştır. Bunun nedeni $\mathrm{BOI்}_{5}$ parametresinde olduğu gibi insan faaliyetleri sonucu göle giren kirleticilerin zamanla artmasından dolayıdır.

Çalışmada elde edilen KOİ verileri YSKY'nde belirlenen KOİ konsantrasyonları ile karşılaştırıldı. Buna göre; KOİ konsantrasyonu 25 mg/L'den küçük olan sular Sınıf-1 kalitesinde sular olarak; 25 ila 50 mg/L arasında olan sular Sınıf-2 kalitesinde sular olarak; 50 ila 70 mg/L arasında olan sular Sınıf-3 kalitesinde sular olarak ve $70 \mathrm{mg} / \mathrm{L}$ 'den büyük olan sular Sınıf-4 kalitesinde sular olarak ifade edilmiştir. Bu çalışmada Haziran, Temmuz ve Ağustos aylarında tespit edilen KOİ konsantrasyonları 25-50 mg/L arasında olduğundan Uzunçayır Barajından mansaplanan yerüstü sularının KOİ açısından su kalite sınıfı Sınıf-2 olarak belirlendi. Literatürde farklı nehirler için çeşitli KOİ konsantrasyonları bildirilmiştir. Ho ve ark. (2019) Klang Nehri’ nde (Malezya) yaptıkları çalışmada nehir suyunun Malezya su kalite indeksi sınıflamasına göre Sınıf 3 (25-50 mg/L) olduğunu gösteren 45 mg/L KOİ konsantrasyonu bildirmişlerdir. Zhao ve ark. (2020)' nın Yellow Nehri (Çin) kollarında yaptıkları çalışmada KOİ değerleri yaklaşık 5 $40 \mathrm{mg} / \mathrm{L}$ arasında değişmiştir. Sözkonusu çalışmada KOİ için ulusal standart değer $20 \mathrm{mg} / \mathrm{L}$ olarak bildirilmiştir. Arman ve ark. (2019) Malezya' da Sg Mengkibol Nehrinde yaptıkları çalışmada KOİ konsantrasyonunu 32,57 mg/L olarak tespit etmişlerdir. Bu sonuca göre Sg Mengkibol Sınıf 3 olarak bildirilmiştir. Güneş ve ark. (2008) Ergene Nehri havzasında yaptıkları çalışmada tekstil endüstrileri organize sanayi bölgesi, deri endüstrileri organize sanayi bölgesi ve Çerkezköy ile Çorlu' daki diğer endüstrilerin atıksularını alan nehir suyunda KOİ konsantrasyonunu $1316 \mathrm{mg} / \mathrm{L}$ olarak, endüstriyel veya evsel atıksu deşarjını almayan nehir suyunda KOİ konsantrasyonunu 29 mg/L olarak bildirmişlerdir. Turan ve Ülkü (2003) Denizli ili Gökpınar ve Çürüksu Çaylarında yaptıkları çalışmada ortalama KOİ değerlerini 43-315 mg/L olarak bildirmişlerdir. Köse ve ark. (2016) Porsuk Çayı' nda yaptıkları çalışmada KOİ konsantrasyonlarını 0,779-25,01 mg/L aralığında tespit etmişlerdir.

\subsection{Nitrat azotu ( $\left.\mathrm{NO}_{3}^{-}-\mathrm{N}\right)$}

Uzunçayır Barajından mansaplanan yerüstü sularında tespit edilen $\mathrm{NO}_{3}{ }^{-}-\mathrm{N}$ konsantrasyonları Şekil 5 'te verilmiştir.

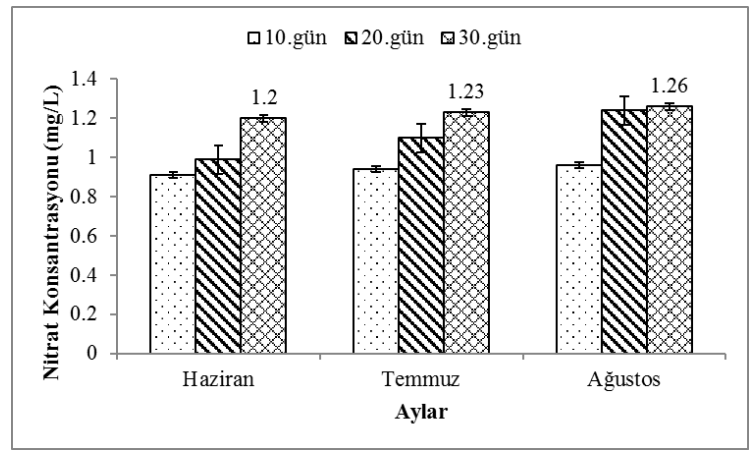

Şekil 5. Uzunçayır Barajından mansaplanan yerüstü sularına ait $\mathrm{NO}_{3}^{-}-\mathrm{N}$ konsantrasyonları 
Şekil 5'e göre Uzunçayır Barajından mansaplanan yerüstü sularında Haziran ayında tespit edilen $\mathrm{NO}_{3}{ }^{-} \mathrm{N}$ konsantrasyonları günlere göre artı̧̧ gösterdi ve en yüksek $\mathrm{NO}_{3}^{-}-\mathrm{N}$ konsantrasyonu 30.gün $1,2 \mathrm{mg} / \mathrm{L}$ olarak, en düşük $\mathrm{NO}_{3}{ }^{-}-\mathrm{N}$ konsantrasyonu 10. gün $0,91 \mathrm{mg} / \mathrm{L}$ olarak tespit edildi. 20. gün ise $\mathrm{NO}_{3}^{-}-\mathrm{N}$ konsantrasyonu $0,99 \mathrm{mg} / \mathrm{L}$ olarak belirlendi. Uzunçayır Barajından mansaplanan yerüstü sularının Haziran ayı ortalama $\mathrm{NO}_{3}{ }^{-}-\mathrm{N}$ konsantrasyonu $1,03 \mathrm{mg} / \mathrm{L}$ olarak hesaplandı. Temmuz ayı $\mathrm{NO}_{3}{ }^{-}-\mathrm{N}^{-}$konsantrasyonları incelendiğinde Haziran ayında olduğu gibi günlere göre $\mathrm{NO}_{3}{ }^{-}-\mathrm{N}$ konsantrasyonları artış gösterdi ve en yüksek $\mathrm{NO}_{3}{ }^{-} \mathrm{N}^{-}$konsantrasyonu 30. gün $1,23 \mathrm{mg} / \mathrm{L}$ olarak en düşük $\mathrm{NO}_{3}^{-}-\mathrm{N}$ konsantrasyonu 10 . gün $0,94 \mathrm{mg} / \mathrm{L}$ olarak belirlendi. Uzunçayır Barajından mansaplanan yerüstü sularının Temmuz ayı ortalama $\mathrm{NO}_{3}{ }^{-}-\mathrm{N}$ konsantrasyonu $1,09 \mathrm{mg} / \mathrm{L}$ olarak hesaplandı. Ağustos ayı $\mathrm{NO}_{3}{ }^{-}-\mathrm{N}^{-}$konsantrasyonları incelendiğinde Haziran ve Temmuz ayında olduğu gibi günlere göre artı̧ gösterdi ve Ağustos ayında tespit edilen en yüksek $\mathrm{NO}_{3}{ }^{-}-\mathrm{N}$ konsantrasyonları 30. gün $1,26 \mathrm{mg} / \mathrm{L}$ en düşük $\mathrm{NO}_{3}^{-}-\mathrm{N}$ konsantrasyonu 10 . gün $0,96 \mathrm{mg} / \mathrm{L}$ 'dir. Uzunçayır Barajından mansaplanan yerüstü sularının Ağustos ayı ortalama $\mathrm{NO}_{3}{ }^{-}-\mathrm{N}$ konsantrasyonu $1,15 \mathrm{mg} / \mathrm{L}$ olarak hesaplandı. Yaz mevsimi $\mathrm{NO}_{3}^{-}-\mathrm{N}^{-}$konsantrasyonları karşılaşıırıldığında $\mathrm{NO}_{3}{ }^{-}-\mathrm{N}$ konsantrasyonlarının aylara göre artış gösterdiği belirlendi. Bunun asıl nedeninin antropojenik etkiler (tarımsal faaliyetler vb. gibi) olabileceği düşünülmektedir. Bayhan ve ark. (2016), Ömerli Baraj Gölünün su kalitesinin belirlenmesine yönelik yaptıkları çalışmada nitrat azotu seviyesini $2 \mathrm{mg} / \mathrm{L}$ seviyesinde belirleyerek baraj gölünün su kaliesini Sınıf-2 olarak tespit etmişlerdir.

Uzunçayır Barajından mansaplanan yerüstü sularında tespit edilen $\mathrm{NO}_{3}^{-}-\mathrm{N}$ konsantrasyonları YSKY'nde belirlenen değerlerle mukayese edildi. YSKY'nde $\mathrm{NO}_{3}{ }^{-} \mathrm{N}$ konsantrasyonu $3 \mathrm{mg} / \mathrm{L}$ 'den küçük olan sular Sınıf-1 kalitesinde sular olarak; 3 ila $10 \mathrm{mg} / \mathrm{L}$ arasında olan sular Sinıf-2 kalitesinde sular olarak; 10 ila $20 \mathrm{mg} / \mathrm{L}$ arasında olan sular Sinıf-3 kalitesinde sular olarak ve $20 \mathrm{mg} / \mathrm{L}$ 'den büyük olan sular Sınıf-4 kalitesinde sular olarak ifade edilmiştir. Bu çalışmada, Uzunçayır Barajından mansaplanan yerüstü sularına ait $\mathrm{NO}_{3}{ }^{-} \mathrm{N}$ konsantrasyonları $3 \mathrm{mg} / \mathrm{L}^{\prime}$ den küçük olduğu için $\mathrm{NO}_{3}{ }^{-} \mathrm{N}$ açısından su kalite sınıfı Sinıf-1 olarak belirlendi. Algal büyümeyi sınırlayan veya arttıran önemli faktörlerden birisi nitrat azotudur. Nitrat azotunun sulardaki normal değerleri $1-10 \mathrm{mg} / \mathrm{L}$ 'dir (Köse ve ark., 2016). Bu çalışmada elde edilen nitrat azotu konsantrasyonlarının $(<3 \mathrm{mg} / \mathrm{L})$ bu aralıkta kaldığı görülmektedir. Köse ve ark. (2016) Porsuk Çayı' nda yaptıkları çalışmada nitrat azotu konsantrasyonlarını 0,208-338 mg/L aralığında tespit etmişlerdir.

\section{5. İstatistiksel Çalışmalar}

$\mathrm{Bu}$ çalışmada, Uzunçayır Barajından mansaplanan yerüstü sularına ait $\mathrm{pH}$, sıcaklık, Eİ, KOİ, $\mathrm{BO}_{5}, \mathrm{NO}_{3}^{-}-\mathrm{N}^{2}$ konsantrasyonları Haziran, Temmuz ve Ağustos aylarında tespit edildi. Aylara göre elde edilen verilerin her bir parametre ile arasındaki ilişki istatistiksel olarak değerlendirildi. Bu çerçevede, Haziran, Temmuz ve Ağustos aylarında parametreler arasındaki istatistiksel ilişki Tablo 2, Tablo 3 ve Tablo 4'de verilmiştir.

Tablo 2. Haziran ayı parametreler arasındaki ilişki

\begin{tabular}{|c|c|c|c|c|c|c|c|}
\hline & & $\mathrm{pH}$ & Sicaklık & Eİ & $\mathrm{BOI}_{5}$ & KOİ & $\mathrm{NO}_{3}{ }^{-}-\mathrm{N}$ \\
\hline \multirow{2}{*}{$\mathrm{pH}$} & Pearson korelasyon & 1 & & & & & \\
\hline & Sig. & & & & & & \\
\hline \multirow{2}{*}{ Sicaklık } & Pearson korelasyon & $1,000^{* *}$ & 1 & & & & \\
\hline & Sig. &, 000 & & & & & \\
\hline \multirow{2}{*}{ Eİ } & Pearson korelasyon &, 327 &, 327 & 1 & & & \\
\hline & Sig. & ,788 & ,788 & & & & \\
\hline \multirow{2}{*}{$\mathrm{BOI}_{5}$} & Pearson korelasyon & ,982 & ,982 &, 500 & 1 & & \\
\hline & Sig. &, 121 &, 121 & ,667 & & & \\
\hline \multirow{2}{*}{ KOİ } & Pearson korelasyon & ,933 & ,933 &,- 034 & 849 & 1 & \\
\hline & Sig. & ,234 &, 234 & ,978 &, 355 & & \\
\hline \multirow{2}{*}{$\mathrm{NO}_{3}^{-}-\mathrm{N}$} & Pearson korelasyon & 968 & ,968 &, 554 & ,998* & 813 & 1 \\
\hline & Sig. &, 161 &, 161 & 626 &, 040 & ,395 & \\
\hline
\end{tabular}

**. Korelasyon 0,01 seviyesinde önemlidir (2-yollu). *. Korelasyon 0,05 seviyesinde önemlidir (2-yollu).

Tablo 2 incelendiğinde Uzunçayır Barajından mansaplanan yerüstü sularında tespit edilen pH değerleri ile sıcaklık değerleri arasında önemli bir korelasyon olduğu belirlendi $\left(\mathrm{R}^{2}=1, \mathrm{p}=0,01\right)$. Ayrıca, Nitrat konsantrasyonları ile $\mathrm{BO}_{5}$ konsantrasyonları arasında da önemli bir korelasyon olduğu belirlendi $\left(\mathrm{R}^{2}=0,998, \mathrm{p}=0,05\right)$. KOİ konsantrasyonları ile Eİ değerleri arasında negatif yönlü ve

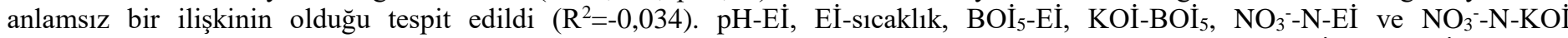
parametreleri arasında pozitif yönlü bir ilişki olduğu ancak korelasyonların kuvvetli olmadığı belirlendi. BO $\dot{I}_{5}-\mathrm{pH}, \mathrm{BO}_{5}$-sıcaklık, KOİ-pH, KOİ-sıcaklık, $\mathrm{NO}_{3}^{-}-\mathrm{N}-\mathrm{pH}$ ve $\mathrm{NO}_{3}^{-}-\mathrm{N}$-sıcaklık parametreleri arasında pozitif yönlü ve önemli bir korelasyon olduğu belirlendi.

Tablo 3. Temmuz ayı parametreler arasındaki ilişki

\begin{tabular}{|c|c|c|c|c|c|c|c|}
\hline & & $\mathrm{pH}$ & Sicaklik & Eİ & $\mathrm{BOI}_{5}$ & KOİ & $\mathrm{NO}_{3}{ }^{-}-\mathrm{N}$ \\
\hline $\mathrm{pH}$ & Pearson korelasyon & & & & & & \\
\hline
\end{tabular}




\begin{tabular}{|c|c|c|c|c|c|c|c|}
\hline & Sig. & & & & & & \\
\hline \multirow{2}{*}{ Sicakl1k } & Pearson korelasyon &,- 866 & 1 & & & & \\
\hline & Sig. & ,333 & & & & & \\
\hline \multirow{2}{*}{ Eİ } & Pearson korelasyon & ,423 & ,086 & 1 & & & \\
\hline & Sig. & ,722 & ,945 & & & & \\
\hline \multirow{2}{*}{$\mathrm{BOİ}_{5}$} & Pearson korelasyon &,- 500 & ,866 &, 573 & 1 & & \\
\hline & Sig. & ,667 & ,333 & ,612 & & & \\
\hline \multirow{2}{*}{ KOİ } & Pearson korelasyon &,- 596 & ,918 & ,475 & ,993 & 1 & \\
\hline & Sig. &, 593 & ,260 & ,685 & ,073 & & \\
\hline \multirow{2}{*}{$\mathrm{NO}_{3}-\mathrm{-N}$} & Pearson korelasyon &,- 447 &, 835 & 621 & ,998* & ,985 & 1 \\
\hline & Sig. &, 705 & ,371 &, 574 & ,038 &, 111 & \\
\hline
\end{tabular}

Tablo 3 incelendiğinde Nitrat ile $\mathrm{BOI}_{5}$ arasında pozitif ve anlamlı bir ilişkinin olduğu görüldü $\left(\mathrm{R}^{2}=0,998, \mathrm{p}=0,05\right)$. Sıcaklık-pH,

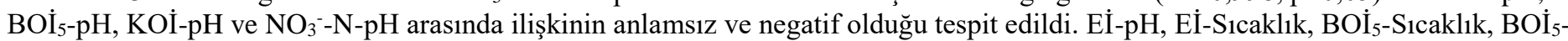
Eİ, KOİ-Eİ, $\mathrm{NO}_{3}^{-}{ }^{-}-\mathrm{N}-S 1 c a k l ı k$ ve $\mathrm{NO}_{3}{ }^{-}-\mathrm{N}$-Eİ arasında pozitif yönde ve anlamlı bir ilişki olduğu ancak korelasyonların zayıf olduğu belirlendi. KOİ-Sıcaklık, KOİ-BOİ ve Nitrat-KOİ arasındaki ilişkilerin pozitif ve anlamlı olduğu, korelasyonların ise $\mathrm{NO}_{3}{ }^{-}{ }^{-}{ }^{-}-\mathrm{BOİ}_{5}{ }^{\prime}$ de olduğu gibi yüksek olduğu belirlendi.

Tablo 4. Ağustos ayl parametreler arasındaki ilişki

\begin{tabular}{|c|c|c|c|c|c|c|c|}
\hline & & $\mathrm{pH}$ & Sicaklık & Eİ & $\mathrm{BOI}_{5}$ & KOİ & $\mathrm{NO}_{3}{ }^{-}-\mathrm{N}$ \\
\hline \multirow{2}{*}{$\mathrm{pH}$} & Pearson korelasyon & 1 & & & & & \\
\hline & Sig. & & & & & & \\
\hline \multirow{2}{*}{ Sicaklik } & Pearson korelasyon &,$- 998^{*}$ & 1 & & & & \\
\hline & Sig. &, 040 & & & & & \\
\hline \multirow{2}{*}{ Eİ } & Pearson korelasyon &,- 756 & ,714 & 1 & & & \\
\hline & Sig. &, 454 & ,494 & & & & \\
\hline \multirow{2}{*}{$\mathrm{BOI}_{5}$} & Pearson korelasyon &,- 929 & ,950 & ,459 & 1 & & \\
\hline & Sig. &, 242 & ,202 & 696 & & & \\
\hline \multirow{2}{*}{ KOİ } & Pearson korelasyon &,- 981 & ,967 & 869 &, 839 & 1 & \\
\hline & Sig. &, 125 &, 164 &, 330 & 367 & & \\
\hline \multirow{2}{*}{$\mathrm{NO}_{3}^{-}-\mathrm{N}$} & Pearson korelasyon &,- 963 & ,944 & ,905 & ,794 &, $997^{*}$ & 1 \\
\hline & Sig. &, 174 &, 214 &, 280 & ,416 &, 050 & \\
\hline
\end{tabular}

*. Korelasyon 0,05 seviyesinde önemlidir (2-yollu).

Tablo 4 incelendiğinde $\mathrm{NO}_{3}{ }^{-}$-N-KOİ arasında pozitif yönde, anlamlı ve yüksek bir korelasyon olduğu belirlendi $\left(\mathrm{R}^{2}=0,997\right.$, $\mathrm{p}=0,05)$. $\mathrm{NO}_{3}-\mathrm{N}-\mathrm{KOII}$ arasındaki ilişkinin aksine Sıcaklık-pH arasında negatif yönde ancak 0,05 seviyesinde yüksek bir korelasyon olduğu belirlendi $\left(\mathrm{R}^{2}=-0,998, \mathrm{p}=0,05\right)$. Eİ-pH, $\mathrm{BOI}_{5}-\mathrm{pH}, \mathrm{KOI}-\mathrm{pH}$ ve $\mathrm{NO}_{3}{ }^{-}-\mathrm{N}-\mathrm{pH}$ arasında negatif yönde bir ilişki olduğu tespit edildi.

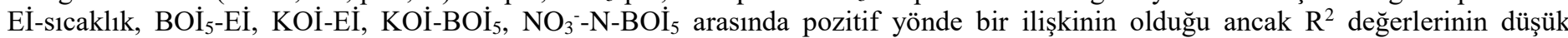
değerler aldığ 1 belirlendi. BOİ ${ }_{5}$-Sıcaklık, KOİ-sıcaklık, $\mathrm{NO}_{3}{ }^{-} \mathrm{N}-$-sıcaklık ve $\mathrm{NO}_{3}{ }^{-}-\mathrm{N}$-Eİ arasında ise pozitif yönde ve anlamlı bir ilişkinin olduğu ve $\mathrm{R}^{2}$ değerlerinin 0,90 'dan büyük değerler aldığı belirlendi.

\section{Sonuç}

Tunceli ilinin önemli su kaynaklarından biri olan Munzur nehri üzerine kurulu Uzunçayır Barajından mansaplanan yerüstü sularının su kalitesinin belirlenmesi amaçlanmıştır. Su kalitesinin belirlenmesinin amacı, barajlardan mansaplanan su kütlesinin hangi amaçla kullanılıp kullanılamayacağının değerlendirilmesidir. Bu çerçevede, Uzunçayır Barajından mansaplanan yerüstü sularının $\mathrm{pH}$, sicaklık, Eİ, KOİ, $\mathrm{BOİ}_{5}$ ve nitrat konsantrasyonları yaz mevsimi (haziran, temmuz ve ağustos) boyunca izlenmiştir. Parametreler arasındaki ilişkiler aylara göre incelendiğinde Haziran ayında $\mathrm{pH}$ değerleri ile sıcaklık değerleri arasında önemli bir korelasyon olduğu $\left(\mathrm{R}^{2}=1, \mathrm{p}=0,01\right)$, Temmuz ayında $\mathrm{NO}_{3}^{-}-\mathrm{N}$ ile BOİं5 $_{5}$ arasında pozitif ve anlamlı bir ilişkinin olduğu $\left(\mathrm{R}^{2}=0,998, \mathrm{p}=0,05\right)$ ve Ağustos ayında $\mathrm{NO}_{3}-\mathrm{N}-$ KOİ arasında pozitif yönde, anlamlı ve yüksek bir korelasyon olduğu belirlendi $\left(\mathrm{R}^{2}=0,997, \mathrm{p}=0,05\right)$. Elde edilen verilere göre Uzunçayır Barajından mansaplanan yerüstü suları $\mathrm{pH}$, Eİ, BOİ 5 ve $\mathrm{NO}_{3}-\mathrm{N}$ açısından Sınıf-1 kalitesinde bir su olarak, KOİ açısından ise Sınıf-2 kalitesinde bir su olarak belirlenmiştir. Ülkemizde su kalitesinin sınıflandırılması YSKY'nde 
ayrıntılı bir şekilde verilmiştir. Bu çerçevede, yüksek kaliteli sular olarak da ifade edilen "çok iyi” su durumunu gösteren sular Sınıf-1 kalitesindeki sular olarak belirtilmektedir. Bu sular içme suyu olma potansiyeli yüksek olan yerüstü suları, yüzme gibi vücut teması gerektirenler dahil rekreasyonel maksatlar için kullanılabilir suları, alabalık üretimi için kullanılabilir nitelikte suları ve hayvan üretimi ve çiftlik ihtiyacı için kullanılabilir nitelikteki suları kapsamaktadır. Az kirlenmiş su olarak da ifade edilen "iyi su" durumunu gösteren sular Sınıf-2 kalitesindeki sular olarak ifade edilmektedir. Bu sular içme suyu olma potansiyeli olan yerüstü sularını, rekreasyonel maksatlar için kullanılabilir nitelikteki suları, alabalık dışında balık üretimi için kullanılabilir nitelikteki suları ve Mer-i mevzuat ile tespit edilmiş olan sulama suyu kalite kriterlerini sağlamak şartıyla sulama suyu olarak kullanılabilecek suları kapsamaktadır. Sonuç olarak Uzunçayır Barajından mansaplanan yerüstü sularını KOİ parametresi hariç Sınıf-1 kalitesinde bir su olarak tanımlayabiliriz.

\section{Kaynakça}

Arman, N.Z., Salmiati, S., Said, M.I.M., Aris, A. (2019). Development of macroinvertebrate-based multimetric index and establishment of biocriteria for river health assessment in Malaysia. Ecological Indicators, 104(2019), 449-458.

Azizullah, A., Khattak, M.N.K., Richter, P., Häder, D.P. (2011). Water pollution in Pakistan and its impact on public health-a review, Environ. Int., 37(2011), 479-497.

Bashir, N., Saeed, R., Afzaal, M., Ahmad, A., Hameed, S. (2020). Water quality assessment of lower Jhelum canal in Pakistan by using geographic information system (GIS). Groundwater for Sustainable Development, 10(2020), Article 100357.

Bayhan H., Erguven G.O., Akkoyunlu A., Kanat G. (2017). The Assessment of Water Quality in Omerlı Dam Reservoir, Istanbul, Turkey. Fresenius Environmental Bulletin., 26 (1a) (2017), 977-988

Bloesch, J., Sandu, C., Janning, J. (2012). Challenges of an integrative water protection and river basin management policy: The Danube case. River Syst., 20(2012), 129-144.

Cikcikoglu, N.C., Demirbilek D., Erguven G.O., Kayar R., Basaran S., Tulpar D. (2018). The determination of present and possible environmental risks in solid waste dumping site, Tunceli, Turkey. Environmental Earth Sciences, 77:622

Chapman, D.V., Bradley, C., Gettel, G.M., Hatvani, I.G., Varbiro, G. (2016). Developments in water quality monitoring and management in large river catchments using the Danube River as an example. Environmental Science \& Policy, 64(2016), 141154.

Crosa, G., Froebrich, J., Nikolayenko, V., Stefani, F., Gallid, P., Calamari, D. 2006. Spatial and seasonal variations in the water quality of the Amu Darya river (Central Asia). Water Res., 40(2006), 2237-2245.

Galán-Martín, A., Vaskan, P., Antón, A., Esteller, L.J., Gonzalo, G. (2017). Multi-objective optimization of rained and irrigated agricultural areas considering production and environmental criteria: a case study of wheat production in Spain. J. Clean. Prod., 140(2017), 816-830.

Güneş, E.H., Güneş, Y., Talınlı, İ. (2008). Toxicity evaluation of industrial and land base sources in a river basin. Desalination, 226(2008), 348-356.

Herdendorf, C.E. (1982). Large lakes of the world. Journal of Great Lakes Research, 8(1982), 379-412.

Herdendorf, C.E. (1990). Distribution of the world's large lakes. M.T. Max, C. Serruya (Eds.), Large lakes: Ecological structure and function, Springer, Berlin Heidelberg (1990), 3-38s.

Ho, J.Y., Afan, H.A., El-Shafie, A.H., Koting, S.B., Mohd, N.S., Jaafar, W.Z.B., Hin, L.S., Malek, M.A., Ahmed, A.N., Melini, W.H., Mohtar, W., Elshorbagy, A., El-Shafie, A. (2019). Towards a time and cost effective approach to water quality index class prediction. Journal of Hydrology, 575(2019), 148-165.

Huang, J., Huang, Y., Zhang, Z. (2014). Coupled effects of natural and anthropogenic controls on seasonal and spatial variations of river water quality during baseflow in a coastal watershed of Southeast China. PLoS One, 9(2014), e91528.

Iqbal, J., Shah, N.S., Sayed, M., Muhammad, N. (2020). Deep eutectic solvent-mediated synthesis of ceria nanoparticles with the enhanced yield for photocatalytic degradation of flumequine under UV-C. J. Water Process. Eng., 33(2020), 101012.

Jiang, Y., Xu, X., Huang, Q., Huo, Z., Huang, G. (2016). Optimization regional irrigation water use by integrating a two-level optimization model and an agro-hydrological model. Agric. Water Manage., 178(2016), 76-88.

Korkanç, S.Y., Kayıkçı, S., Korkanç, M. (2017). Evaluation of spatial and temporal water quality in the Akkaya dam watershed (Niğde, Turkey) and management implications. Journal of African Earth Sciences, 129(2017), 481-491.

Köse, E., Çiçek, A., Emiroğlu, Ö., Tokatlı, C., Uğurluoğlu, A., Başkurt, S., Aksu, S., Uylaş, M. (2016). Water quality assess ment of Porsuk stream basin. Biological Diversity and Conservation, 9(2016), 119-126.

Lehner, B., Döll, P. (2004). Development and validation of a global database of lakes, reservoirs and wetlands. Journal of Hydrology, 296(2004), 1-22. 
Levidow, L., Zaccarla, D., Maia, R., Vivas, E., Yodorovic, M., Scardigno, A. (2014). Improving water-efficient irrigation: prospects and difficulties of innovative practices. Agric. Water Manage., 146(2014), 84-94.

Li, M., Xu, Y., Fu, O., Singh, V.P., Liu, D., Li, T. (2020a). Efficient irrigation water allocation and its impact on agricultural sustainability and water scarcity under uncertainty. Journal of Hydrology, 586(2020), Article 124888.

Li, L., Iqbal, J., Zhu, Y., Wang, F., Zhang, F., Chen, W., Wu, T., Du, Y. (2020b). Chitosan/Al2O3-HA nanocomposite beads for efficient removal of estradiol and chrysoidin from aqueous solution. Int. J. Biol. Macromol., 145(2020), 686-693.

Ouyang, Y. (2005). Evaluation of river water quality monitoring stations by principal component analysis. Water Res., 39(2005), 2621-2635.

Paca, J.M., Santos, F.M., Pires, J.C.M., Leitao, A.A., Boaventura, R.A.R. (2019). Quality assessment of water intended for human consumption from Kwanza, Dande and Bengo rivers (Angola). Environmental Pollution, 254(2019), Article 113037.

Rahman, M.M., Howladar, M.F., Hossain, M.A., Muzemder, A.T.M., Al Numanbakth, M.A. (2020). Impact assessment of anthropogenic activities on water environment of tillai river and its surroundings, barapukuria thermal power plant. Dinajpur, Bangladesh, Groundw. Sustain. Dev., 10(2020), 100310.

Sarkar, S.K., Saha, M., Takada, H., Bhattacharya, A., Mishra, P., Bhattacharya, B. (2007). Water quality management in the lower stretch of the river Ganges, east coast of India: an approach through environmental education. J. Clean. Prod., 15(2007), 15591567.

Shirani, Z., Santhosh, C., Iqbal, J., Bhatnagar, A. (2018). Waste Moringa oleifera seed pods as green sorbent for efficient removal of toxic aquatic pollutants. J. Environ. Manag., 227(2018), 95-106.

Sommerwerk, N., Bloesch, J., Paunović, M., Baumgartner, C., Venohr, M., Schneider-Jacoby, M., Hein, T., Tockner, K. (2010). Managing the world's most international river: the Danube River Basin. Mar. Freshwater Res., 61(2010), 736-748.

Subedi, N., Lähde, A., Abu-Danso, E., Iqbal, J., Bhatnagar, A. (2019). A comparative study of magnetic chitosan (Chi@Fe3O4) and graphene oxide modified magnetic chitosan (Chi@ $\mathrm{Fe} 3 \mathrm{O} 4 \mathrm{GO})$ nanocomposites for efficient removal of $\mathrm{Cr}(\mathrm{VI})$ from water. Int. J. Biol. Macromol., 137(2019), 948-959.

Turan, F., Ülkü, G. (2013). Gökpınar ve Çürüksu Çaylarının Kirlilik Parametre ve Yüklerinin İzlenmesi. Pamukkale Üniversitesi Mühendislik Bilimleri Dergisi, 19(2013), 133-144.

Ustaoğlu, F., Tepe, Y. (2019). Water quality and sediment contamination assessment of Pazarsuyu Stream, Turkey using multivariate statistical methods and pollution indicators. Int. Soil Water Conserv. Res. (2019), 10.1016/j.iswcr.2018.09.001

Ustaoğlu, F., Tepe, Y., Taş, B. (2020). Assessment of stream quality and health risk in a subtropical Turkey river system: A combined approach using statistical analysis and water quality index. Ecological Indicators, 113 (2020), Article 105815.

Wang, J., Sheng, Y., Tong, T.S.D. (2014). Monitoring decadal lake dynamics across the Yangtze Basin downstream of Three Gorges Dam. Remote Sensing of Environment, 152(2014), 251-269.

YSKY, 2012. Yerüstü Su Kalitesi Yönetmeliği, 30.11.2012 Tarih ve 28483 sayılı Resmi Gazete.

Zhao, M.M., Wang, S.M., Chen, Y.P., Wu, J.H., Xue, L.-G., Fan, T.T. (2020). Pollution status of the Yellow River tributaries in middle and lower reaches. Science of The Total Environment, 722(2020), Article 137861.

Zhou, F., Huang, G.H., Guo, H.C., Zhang, W., Hao, Z.J. (2007). Spatio-temporal patterns and source apportionment of coastal water pollution in eastern Hong Kong. Water Res., 41(2007), 3429-3439. 